\title{
Purification of human primary neuroblastomas by magnetic beads and their in vitro culture
}

\author{
HIROKO NAKANISHI $^{1,2}$, TOSHINORI OZAKI ${ }^{1}$, YOUKO NAKAMURA ${ }^{1}$, KOHEI HASHIZUME $^{3}$, \\ TADASHI IWANAKA ${ }^{2}$ and AKIRA NAKAGAWARA ${ }^{1}$ \\ ${ }^{1}$ Division of Biochemistry, Chiba Cancer Center Research Institute, 666-2 Nitona, Chuoh-ku, Chiba 260-8717; \\ ${ }^{2}$ Department of Pediatric Surgery, Graduate School of Medicine, University of Tokyo, 7-3-1 Hongo, Bunkyo-ku, \\ Tokyo 113-0033; ${ }^{3}$ Tokyo-West Tokushukai Hospital, 3-1-1 Matsubara-cho, Akishima 196-0003, Japan
}

Received January 2, 2007; Accepted February 20, 2007

\begin{abstract}
In the present study we have successfully isolated neuroblastoma cells from primary human neuroblastoma tissues by using a magnetic bead-mediated purification system. Since primary neuroblastoma tissues contained CD3and CD19-positive lymphocytes, total cell suspensions were prepared and incubated with magnetic beads coated with antiCD3 or with anti-CD19 antibody. After magnetic separation, unbound materials were recovered and analyzed by immunohistochemical staining for NB84, one of the neuroblastoma markers. Immunohistochemical and FACS analyses demonstrated that NB84-positive cells were enriched in the unbound fraction. Subsequently, unbound materials were seeded on cell culture plates and maintained at $37^{\circ} \mathrm{C}$ overnight. After incubation, non-adherent cells were collected and stained with anti-NB84 antibody. Under our experimental conditions, a significant increase in the number of NB84-positive cells was observed. Furthermore, our purified NB84-positive cells responded to all-trans retinoic acid and nerve growth factor better than the initial primary cells. Collectively, our present results suggest that magnetic bead-mediated purification enriches neuroblastoma cells which retain their biological properties.
\end{abstract}

\section{Introduction}

Neuroblastoma is one of the most common early childhood solid tumors of the peripheral nervous system arising from an as yet unidentified population of neural crest cells (1), and is clinically and cytogenetically divided into two major sub-

Correspondence to: Dr Akira Nakagawara, Division of Biochemistry, Chiba Cancer Center Research Institute, 666-2 Nitona, Chuoh-ku, Chiba 260-8717, Japan

E-mail: akiranak@chiba-cc.jp

Key words: NB84, neuroblastoma, nerve growth factor, retinoic acid groups with distinct biological properties (2). One subgroup of tumors in the early stages displays favorable prognosis and usually occurs in patients $<1$ year of age. They have no MYCN gene amplification and often differentiate and/or regress spontaneously. In sharp contrast, tumors that occur in patients $>1$ year of age usually possess $M Y C N$ gene amplification and allelic loss in the distal part of the short arm of chromosome 1, and are often aggressive with an unfavorable prognosis in spite of an intensive multimodal therapy (3). Additionally, it has been shown that high expression levels of neurotrophin receptor genes $\operatorname{Trk} A$ and $\operatorname{Trk} B$ are favorable and unfavorable prognostic indicators, respectively (4-6). However, the precise molecular mechanisms behind disease progression and tumor regrowth are still unclear. From a clinical point of view, aggressive neuroblastomas are the most problematic, and it is quite difficult to decide which therapeutic strategy is suitable.

As described previously (7), neuroblastomas exhibit heterogenous morphologies with tumors composed of a mixture of neuroblasts, ganglion cells, non-neuronal Schwann-like cells and stromal cells. Indeed, human neuroblastoma-derived cell lines consist of heterogenous subpopulations of cells which show distinct morphological and biochemical features (7-10). The established neuroblastoma cell lines spontaneously give rise to diverse populations of neuroblastic (N-type) and Schwann-like (S-type) cells $(9,10)$. In addition to $\mathrm{N}$ - and $\mathrm{S}$-type cells, cells with intermediate morphology (I-type) have also been cloned (11), and these three subtypes have an ability to interconvert or transdifferentiate spontaneously (12), suggesting that N-type to Stype differentiation might reflect in vivo differentiation of the tumor. To better understand the biological behavior as well as molecular events in vivo, it seems to be important to remove the additional components such as non-neuronal Schwannlike and stromal cells from neuroblastomas in culture.

In the present study, we have obtained successful results isolating neuroblastoma cells from primary neuroblastoma tissues by using magnetic bead-mediated purification.

\section{Materials and methods}

Patient population. Tumors were staged following the International Neuroblastoma Staging System criteria (13). 
The patients were treated according to the protocols proposed by the Japanese Infantile Neuroblastoma Cooperative Study (14) and the Study Group of Japan for Treatment of Advanced Neuroblastoma (15). All patients agreed to participate and provided written informed consent. Our present study was approved by the institutional ethics review committee.

Primary culture. Fresh human neuroblastoma tissues were minced and incubated with RPMI-1640 medium supplemented with $10 \%$ heat-inactivated fetal bovine serum, penicillin (50 U/ml), streptomycin $(50 \mu \mathrm{g} / \mathrm{ml})$ and $100 \mu \mathrm{g} / \mathrm{ml}$ of OPI (Sigma, St. Louis, MO, USA) in the presence of 500 units $/ \mathrm{ml}$ of collagenase (Sigma) at $37^{\circ} \mathrm{C}$ for $1 \mathrm{~h}$. After incubation, tumor tissues were dispersed by using a plastic syringe with an 18-gauge needle, seeded on tissue culture plates precoated with collagen, and cultured at $37^{\circ} \mathrm{C}$ with $5 \% \mathrm{CO}_{2}$ in a humidified incubator. Where indicated, cells were treated with the indicated combinations of all-trans retinoic acid (ATRA, Sigma) and nerve growth factor (NGF, Sigma), and their effects on neurite outgrowth were examined with a phase-contrast microscope.

Purification of neuroblastoma tumors. The magnetic beads were conjugated with anti-mouse IgG. After incubation, the magnetic beads (Dynal, Oslo, Norway) were washed in PBS and then incubated for 4-8 $\mathrm{h}$ with monoclonal anti-CD3 (DHCT1, Ancell, Bayport, MN) or with anti-CD19 (BU12, Ancell) antibody at $4^{\circ} \mathrm{C}$. The indicated beads were mixed and incubated for $1 \mathrm{~h}$ at $4^{\circ} \mathrm{C}$ with cell suspensions before magnetic separation to isolate the two fractions: cells bound to the beads (lymphocytes) versus cells not bound to the beads (neuroblastomas, Schwann cells and fibroblasts). The latter cell fraction was subsequently cultured in a standard medium overnight at $37^{\circ} \mathrm{C}$, and then separated into adherent cells (Schwann cells and fibroblasts) and non-adherent cells (neuroblastomas).

Measurement of cell viability. The trypan blue dye exclusion experiments were carried out by incubating the cell suspension with an equal amount of $0.3 \%$ trypan blue solution (Sigma) for $5 \mathrm{~min}$ at room temperature. After the incubation, the number of cells excluding trypan blue was measured by using a hemocytometer to estimate the number of intact viable cells.

Immunohistochemistry. Neuroblastoma tissues were fixed in $10 \%$ formaldehyde, embedded in paraffin, and 3- $\mu \mathrm{m}$ sections were subjected to immunostaining. Before incubating with anti-NB84 antibody (NB84a, Novocastra Laboratories, Newcastle, UK), the sections were treated with $0.05 \%$ Pronase in $50 \mathrm{mM}$ Tris- $\mathrm{HCl}(\mathrm{pH} \mathrm{7.5)}$ for $5 \mathrm{~min}$. The sections were stained with anti-NB84 antibody at $4^{\circ} \mathrm{C}$ overnight, processed for the biotin-streptavidin method (Nichirei, Tokyo, Japan), and visualized with diaminobenzidine solution. Cell nuclei were stained with hematoxylin and eosin $(\mathrm{H} \& \mathrm{E})$.

Flow cytometry. Cells $\left(3-5 \times 10^{5}\right)$ were washed in ice-cold PBS, and fixed in $0.25 \%$ paraformaldehyde for $15 \mathrm{~min}$ at room temperature. After washing in PBS, cells were incubated with anti-CD3 or with anti-CD19 antibody followed by incubation with FITC-conjugated isotype-specific secondary antibody (Invitrogen, Carlsbad, CA) at $4^{\circ} \mathrm{C}$ for $30 \mathrm{~min}$. After washing in PBS, analysis was performed by FACS flow cytometer (Becton Dickinson, San Diego, CA). Cells were properly gated and histograms [FITC-fluorescence ( $\mathrm{x}$-axis) versus counts (y-axis)] were plotted to illustrate the logarithmic fluorescence intensity.

\section{Results}

Immunohistochemical analysis of human primary neuroblastomas. The 52 examined fresh human primary neuroblastoma samples were divided into 38 non-disseminated tumors with excellent outcome (stage 1,2 and 4s) and 14 disseminated tumors with unfavorable outcome (stage 3 and 4). These primary samples were subjected to primary cultures according to a standard protocol, and their viability was examined by trypan blue dye exclusion assay. Under our experimental conditions, 91 and $94 \%$ of non-disseminated and disseminated cells were viable, respectively (data not shown). In accordance with recent observations (16), the represented immunohistochemical analysis revealed that surgically resected tumor tissues (case 625) contained NB84positive neuroblastoma cells as well as lymphocytes, fibroblasts and Schwann cells (Fig. 1A). Similar results were also obtained in immunohistochemical analysis of total cell suspensions prepared from case 625 (Fig. 1B). NB84 has been considered to be one of the neuroblastoma markers (17).

Purification of neuroblastoma cells by using magnetic beads. To examine the amounts of lymphocytes included in primary neuroblastoma samples, we performed FACS analysis. For this purpose, total cell suspensions prepared from 24 cases including 14 non-disseminated tumors and 10 disseminated tumors were incubated with magnetic beads conjugated with anti-CD3 or with anti-CD19 antibody, and the unbound materials were again subjected to the magnetic bead treatment. Then unbound materials were processed for FACS analysis to determine the number of CD3- or CD19-positive cells. The representative data (case 625) are shown in Fig. 2A. Total cell suspensions contained $41 \%$ CD3-positive cells ( $\mathrm{T}$ cells) but no CD19-positive cells (B cells). As expected, magnetic bead treatment resulted in a complete removal of CD3-positive cells. The cell viability of the bound materials (lymphocyte fractions) derived from non-disseminated and disseminated tumors was 81 and $79 \%$, respectively (data not shown). On the other hand, the cell viability of the unbound materials prepared from non-disseminated and disseminated tumors was 94 and $92 \%$, respectively (data not shown). We then examined the unbound materials by immunohistochemical analysis. As shown in Fig. 2B, NB84-positive cells were relatively enriched after magnetic bead-mediated separation. The unbound materials still contained NB84positive neuroblastoma cells as well as fibroblasts and Schwann cells. According to our preliminary observations, neuroblastoma cells were less adherent than Schwann cells as well as fibroblasts to culture plates (data not shown). To separate NB84-positive neuroblastoma cells from fibroblasts and Schwann cells, the unbound materials were seeded on cell culture plates and incubated at $37^{\circ} \mathrm{C}$ overnight. After incubation, non-adherent cells were recovered and subjected 
A

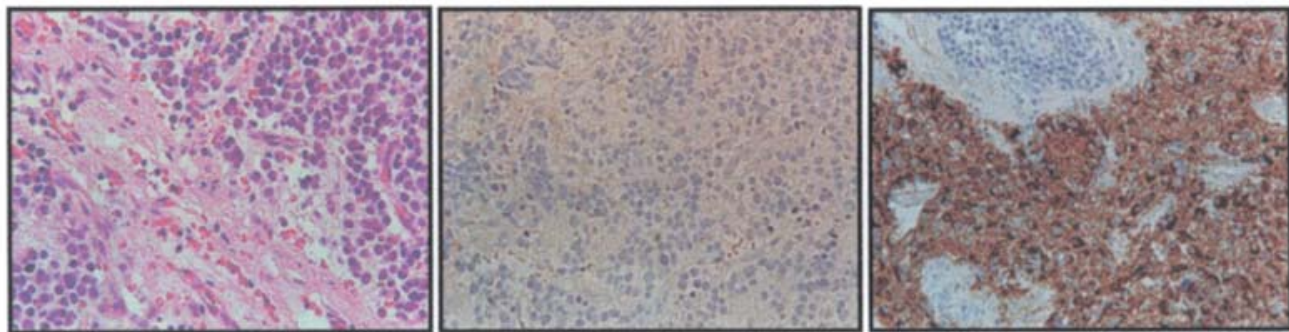

H \&E IgG Anti-NB84

B

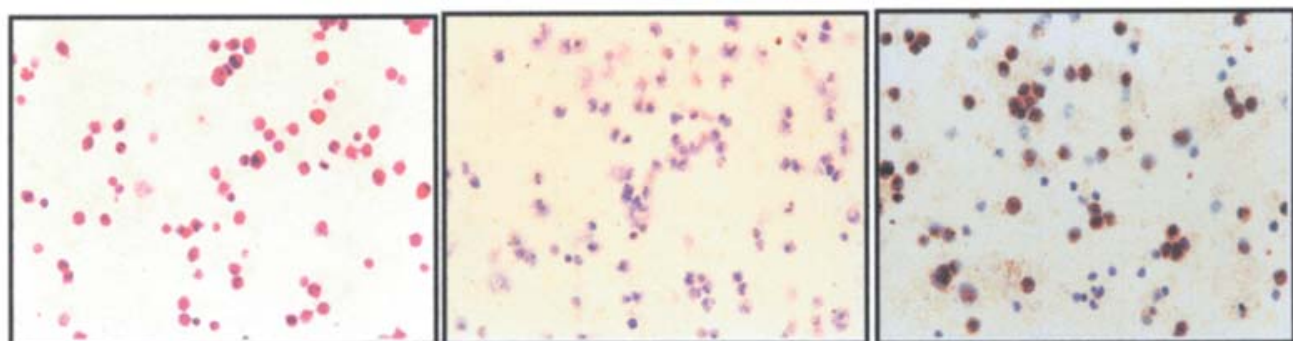

H \&E IgG Anti-NB84

Figure 1. Immunohistochemical staining for NB84 in human primary neuroblastoma tissues. (A) Clinical samples of the patient with neuroblastoma (case 625) were subjected to H\&E staining. Alternatively, these primary samples were processed for immunohistochemical staining with control IgG or with antiNB84 antibody. (B) H\&E and immunohistochemical staining of cell suspensions prepared from primary neuroblastoma (case 625).
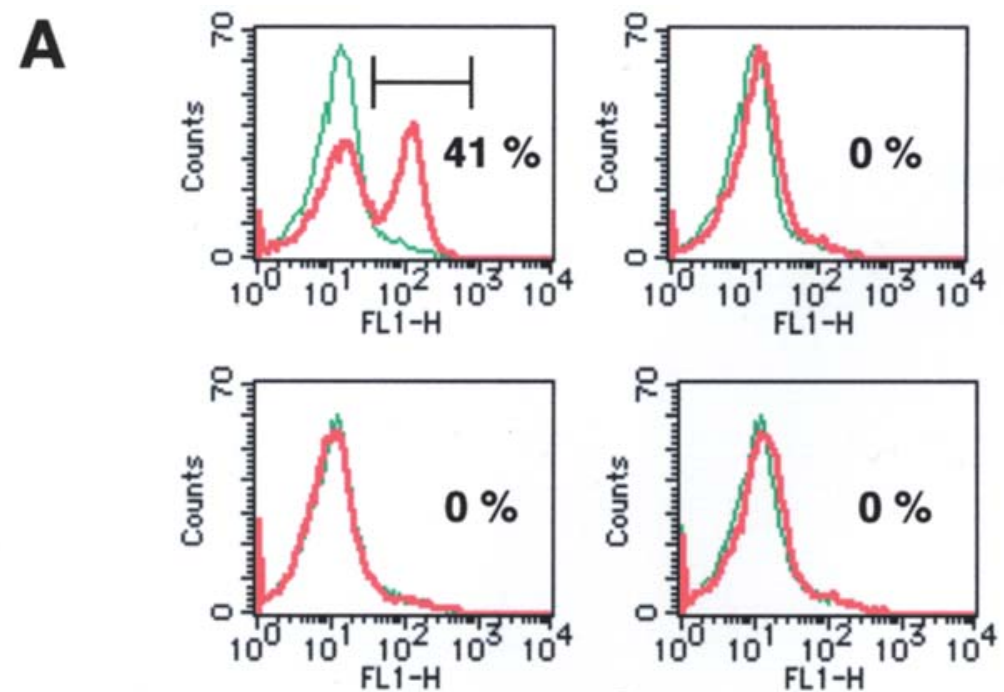

B

C
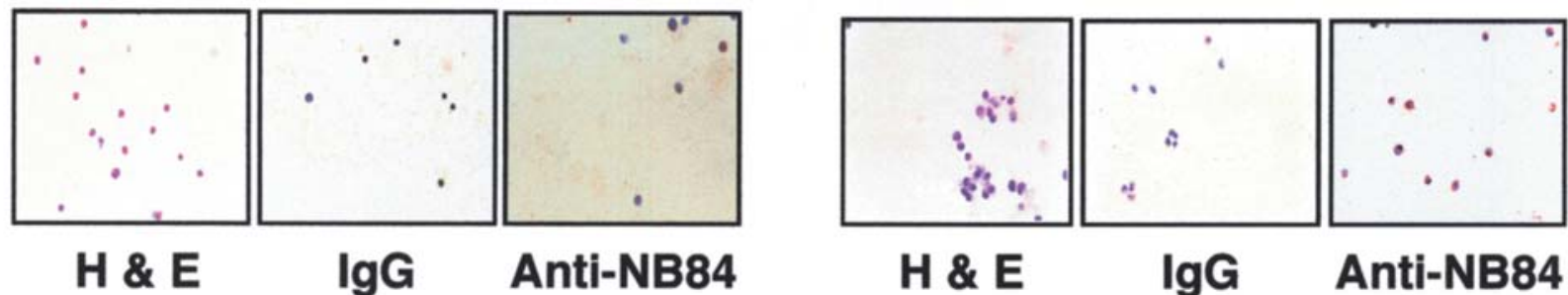

$H \& E$

IgG Anti-NB84

Figure 2. Flow cytometric analysis of primary neuroblastoma. (A) Total cell suspensions prepared from primary neuroblastoma (case 625) were analyzed by flow cytometry for the expression of CD3 and CD19 before and after magnetic separation. (B) Immunohistochemical analysis of neuroblastoma cell suspensions (case 625) after magnetic separation (CD3- and CD19-negative cells). (C) After magnetic separation of neuroblastoma cell suspensions (case 625), CD3- and CD19-negative cells were maintained overnight, and non-adherent cells were collected followed by immunohistochemical staining. 

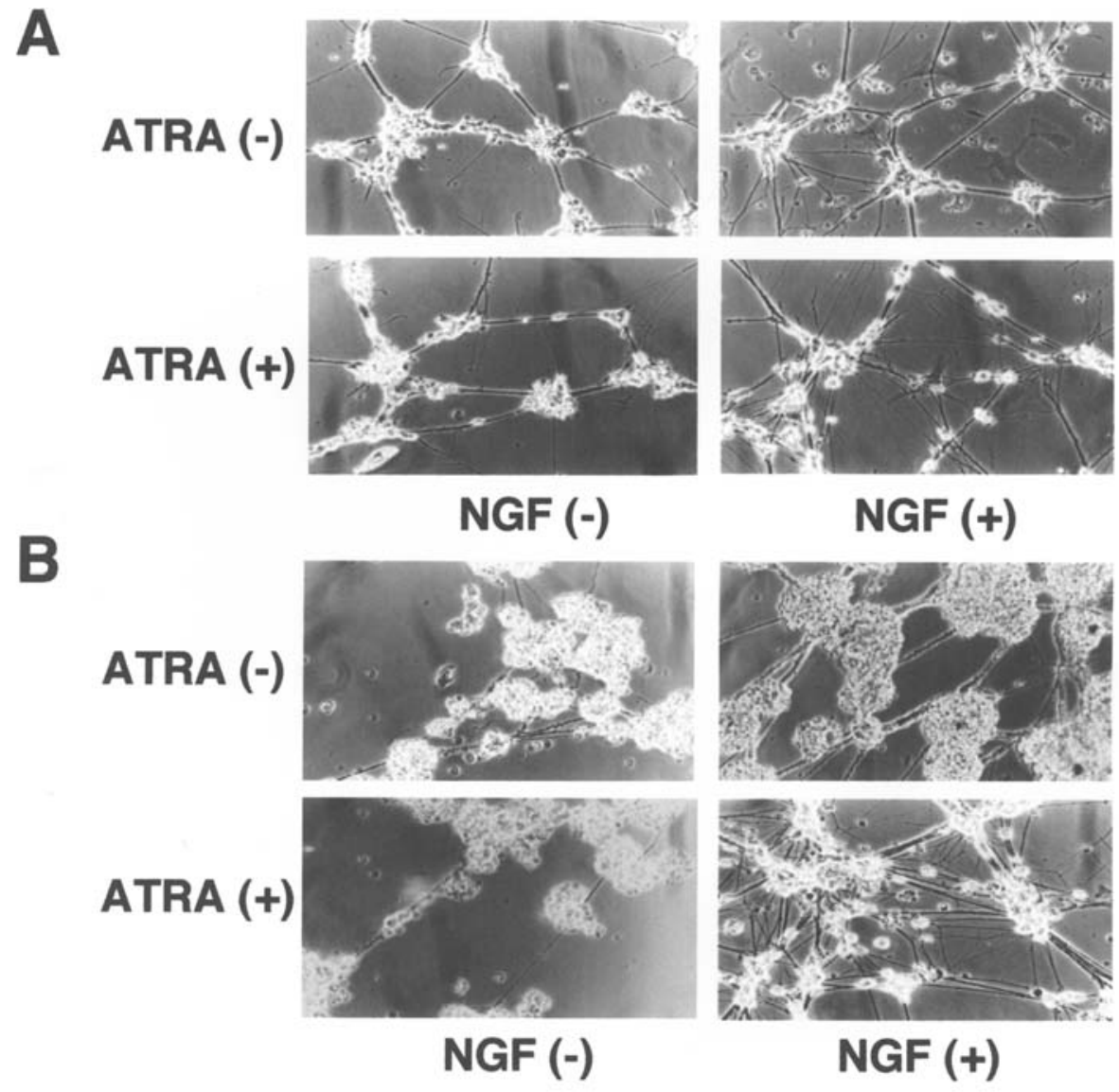

Figure 3. Neurite extension of primary neuroblastomas in response to NGF and/or ATRA. Total cell suspensions (A) and CD3- and CD19-negative nonadherent cells (B) prepared from case 625 were treated with or without the indicated combinations of NGF (100 ng/ml) and ATRA $(5 \mu \mathrm{M})$ for seven days, and their neurite outgrowth was examined.

to immunohistochemical staining with anti-NB84 antibody. As shown in Fig. 2C, NB84-positive neuroblastoma cells were efficiently enriched by our present procedure.

Neurite extension in response to ATRA and/or NGF. To address whether magnetic bead-mediated enrichment of neuroblastoma cells could affect their biological behavior, we compared the degree of neurite outgrowth between cells before and after the selection. To this end, total cell suspensions and CD3- and CD19-negative non-adherent cells prepared from case 625 were cultured in the presence or absence of ATRA and/or NGF. Seven days after treatment, cells were observed with a phase-contrast microscope. Representative data are shown in Fig. 3A and B. ATRA alone had undetectable effects on both cells, whereas NGF treatment led to a formation of neurites in both cells. To note, treatment of CD3and CD19-negative non-adherent cells with the combination of ATRA and NGF significantly enhanced neurite outgrowth as compared with total cell suspensions, suggesting that NB84-positive neuroblastoma cells purified by magnetic bead-mediated separation retain the biological properties of primary neuroblastomas.

\section{Discussion}

To understand the biological properties of neuroblastomas in vivo, it is necessary to isolate neuroblastoma cells from fresh neuroblastoma tissues in culture. As described previously (18), growth factors have an ability to promote proliferation or differentiation of neuroblastoma cells through interactions with their specific receptors. Among them, NGF, which induces normal adrenal cells to differentiate into cells identical to sympathetic neurons, plays a key role in the development of neuroblastomas (19). It has been well established that the high-affinity NGF receptor TrkA gene is highly expressed in low-stage neuroblastomas but not in advanced neuroblastomas (4). Several lines of evidence suggest that NGF responsiveness of neuroblastoma-derived cell lines is closely associated with the expression levels of $\operatorname{TrkA}$ and the low-affinity NGF receptor gene $p 75^{N T R}(20,21)$. Since $p 75^{N T R}$ alone had undetectable effects on NGF responsiveness of neuroblastoma cell lines (22), we sought to isolate neuroblastoma cells from primary neuroblastoma tissues by using magnetic beads coated with anti-p75 ${ }^{\mathrm{NTR}}$ antibody. Under our experimental conditions, we failed to enrich neuroblastoma cells due to diverse expression levels of $\mathrm{p} 75^{\mathrm{NTR}}$ in primary neuroblastoma samples (data not shown).

During the preparation of primary neuroblastoma samples, we noticed that primary neuroblastoma tissues contain substantial amounts of lymphocytes. We then employed magnetic beads coated with anti-CD3 or anti-CD19 antibody to remove lymphocytes from primary neuroblastoma samples. After magnetic separation, the unbound materials were cultured overnight and the non-adherent cells were collected. 
Table I. FACS analysis of advanced neuroblastomas.

\begin{tabular}{|c|c|c|c|c|c|c|c|c|c|}
\hline \multirow[b]{3}{*}{ Case } & \multirow[b]{3}{*}{ Age } & \multirow[b]{3}{*}{ Stage } & \multicolumn{4}{|c|}{ Total cell suspension } & \multicolumn{3}{|c|}{ Cells after treatment with beads } \\
\hline & & & \multicolumn{3}{|c|}{ Lymphocytes } & \multirow{2}{*}{$\frac{\mathrm{NB} \text { cells }}{\mathrm{NB} 84(\%)}$} & \multicolumn{2}{|c|}{ Lymphocytes } & \multirow{2}{*}{$\frac{\mathrm{NB} \text { cells }}{\mathrm{NB} 84(\%)}$} \\
\hline & & & Total $(\%)$ & CD3 (\%) & CD19 (\%) & & CD3 $(\%)$ & CD19 (\%) & \\
\hline 548 & 2 years & 4 & 4 & 4 & 0 & ND & ND & ND & ND \\
\hline 559 & 1 year & 3 & 20 & 20 & 0 & ND & 0 & 0 & ND \\
\hline 564 & 2 years & 4 & 20 & 7 & 13 & ND & 0 & 0 & ND \\
\hline 580 & 9 months & 3 & 21 & 9 & 12 & ND & ND & ND & ND \\
\hline 581 & 1 year & 4 & 31 & 31 & 0 & ND & ND & ND & ND \\
\hline 602 & 1 year & 4 & 13 & 13 & 0 & 17 & 0 & 0 & 50 \\
\hline 603 & 2 years & 4 & 15 & 4 & 11 & ND & ND & ND & ND \\
\hline 613 & 4 years & 4 & 56 & 28 & 28 & 16 & 0 & 0 & 51 \\
\hline 615 & 7 months & 3 & 15 & 11 & 4 & ND & 0 & 0 & ND \\
\hline 649 & 6 years & 4 & 0 & 0 & 0 & 22 & 0 & 0 & 56 \\
\hline
\end{tabular}

ND, not determined

Table II. FACS analysis of neuroblastomas in stages 1, 2 and 4s.

\begin{tabular}{|c|c|c|c|c|c|c|c|c|c|}
\hline \multirow[b]{3}{*}{ Case } & \multirow[b]{3}{*}{ Age } & \multirow[b]{3}{*}{ Stage } & \multicolumn{4}{|c|}{ Total cell suspension } & \multicolumn{3}{|c|}{ Cells after treatment with beads } \\
\hline & & & \multicolumn{3}{|c|}{ Lymphocytes } & \multirow{2}{*}{$\frac{\mathrm{NB} \text { cells }}{\mathrm{NB} 84(\%)}$} & \multicolumn{2}{|c|}{ Lymphocytes } & \multirow{2}{*}{$\frac{\mathrm{NB} \text { cells }}{\mathrm{NB} 84(\%)}$} \\
\hline & & & Total $(\%)$ & CD3 (\%) & CD19 (\%) & & CD3 $(\%)$ & CD19 (\%) & \\
\hline 601 & 9 months & 2 & 28 & 20 & 8 & ND & ND & ND & ND \\
\hline 609 & 7 months & 1 & 58 & 44 & 14 & ND & 0 & 0 & ND \\
\hline 611 & 7 months & $4 \mathrm{~s}$ & 57 & 57 & 0 & ND & 0 & 0 & ND \\
\hline 619 & 9 months & 2 & 83 & 72 & 11 & 50 & 0 & 0 & ND \\
\hline 624 & 8 months & 1 & 96 & 48 & 48 & ND & 40 & 34 & ND \\
\hline 625 & 7 months & 1 & 41 & 41 & 0 & 66 & 0 & 0 & 72 \\
\hline 627 & 7 months & 1 & 15 & 15 & 0 & 0 & 0 & 0 & ND \\
\hline 641 & 7 months & 1 & 0 & 0 & 0 & 64 & 0 & 0 & 65 \\
\hline 643 & 1 year & 1 & 0 & 0 & 0 & 78 & 0 & 0 & 86 \\
\hline 678 & 7 months & 1 & 15 & 14 & 1 & 86 & 2 & 0 & 95 \\
\hline 684 & 8 months & 1 & 4 & 4 & 0 & 95 & 0 & 0 & 97 \\
\hline 687 & 8 months & 1 & 11 & 10 & 1 & 86 & 2 & 1 & 75 \\
\hline 711 & 7 months & 1 & 20 & 19 & 1 & 79 & 0 & 0 & 95 \\
\hline 716 & 8 months & 1 & 20 & 18 & 2 & 22 & 2 & 1 & 60 \\
\hline
\end{tabular}

ND, not determined.

FACS analysis revealed that our procedure successfully enriches NB84-positive viable neuroblastoma cells (Tables I and II), indicating that NB84-positive neuroblastoma cells can be separated from Schwann cells as well as from fibroblasts by taking advantage of their differential adhesion. Moreover, NB84-positive neuroblastoma cells responded to ATRA and NGF, suggesting that our enriched materials retained the biological properties of primary neuroblastomas. Collectively, our magnetic bead-mediated isolation system provides fresh and enriched neuroblastoma cells in culture.

\section{Acknowledgements}

This study was supported in part by a Grant-in-Aid from the Ministry of Health, Labour and Welfare for Third Term Comprehensive Control Research for Cancer, a Grant-in-Aid for Scientific Research on Priority Areas from the Ministry of Education, Culture, Sports, Science and Technology, Japan, a Grant-in-Aid for Scientific Research from Japan Society for the Promotion of Science and Uehara Memorial Foundation. 


\section{References}

1. Brodeur GM: Neuroblastoma: biological insights into a clinical enigma. Nat Rev Cancer 3: 203s216, 2003.

2. Schor NF: Neuroblastoma as a neurobiological disease. J Neurooncol 41: 159-166, 1999.

3. Brodeur GM and Nakagawara A: Molecular basis of clinical heterogeneity in neuroblastoma. Am J Pediatr Hematol Oncol 14: 111-116, 1992

4. Nakagawara A, Arima-Nakagawara M, Scavarda NJ, Azar CG, Cantor $\mathrm{AB}$ and Brodeur GM: Association between high levels of expression of the TRK gene and favorable outcome in human neuroblastoma. N Engl J Med 328: 847-854, 1993.

5. Nakagawara A, Azar CG, Scavarda NJ and Brodeur GM: Expression and function of TRK-B and BDNF in human neuroblastomas. Mol Cell Biol 14: 759-767, 1994.

6. Brodeur GM, Nakagawara A, Yamashiro DJ, Ikegaki N, Liu XG, Azar CG, Lee CP and Evans AE: Expression of TrkA, TrkB and TrkC in human neuroblastomas. J Neurooncol 31: 49-55, 1997.

7. Chen S, Caragine T, Cheung NK and Tomlinson S: Surface antigen expression and complement susceptibility of differentiated neuroblastoma clones. Am J Pathol 156: 1085-1091, 2000.

8. Seeger RC, Rayner SA, Banerjee A, Chung H, Laug WE, Neustein HB and Benedict WF: Morphology, growth, chromosomal pattern and fibrinolytic activity of two new human neuroblastoma cell lines. Cancer Res 37: 1364-1371, 1977.

9. Ross RA, Spengler BA and Chang TD: Transdifferentiation of neuroblastoma cells. J Natl Cancer Inst 71: 741-747, 1983.

10. Spengler BA, Lazarova DL, Ross BA and Biedler JL: Cell lineage and differentiation state are primary determinants of MYCN gene expression and malignant potential in human neuroblastoma cells. Oncol Res 9: 467-476, 1997.

11. Ciccarone V, Spengler BA, Meyers MB, Biedler JL and Ross RA: Phenotypic diversification in human neuroblastoma cells: expression of distinct neural crest lineages. Cancer Res 49: 219-225, 1989.

12. Biedler JL, Spengler BA and Ross RA: Transdifferentiation of human neuroblastoma cells results in coordinate loss of neuronal and malignant properties. Prog Clin Biol Res 271: 265-276, 1988.
13. Brodeau GM, Pritchard J, Berthold F, Carlsen NL, Castel V, Castelberry RP, De Bernardi B, Evans AE, Favrot M, Hedborg F, Kaneko M, Kemshead J, Lampert F, Lee RE, Look AT, Pearson AD, Philip T, Roald B, Sawada T, Seegel RC, Tsuchida Y and Voute PA: Revisions of the international criteria for neuroblastoma diagnosis, staging, and response to treatment. J Clin Oncol 11: 1466-1477, 1993.

14. Matsumura T, Iehara T, Sawada T and Tsuchida Y: Prospective study for establishing the optimal therapy of infantile neuroblastoma in Japan. Med Pediatr Oncol 31: 210, 1998.

15. Kaneko M, Nishihara H, Mugishima H, Ohnuma N, Nakada K, Kawa K, Fukuzawa M, Suita S, Sera Y and Tsuchida Y: Stratification of treatment of stage 4 neuroblastoma patients based on N-myc amplification status: study group of Japan for treatment of advanced neuroblastoma. Med Pediatr Oncol 31: $1-7,1998$.

16. Bomken SN, Redfern K, Wood KM, Reid MM and Tweddle DA: Limitations in the ability of NB84 to detect metastatic neuroblastoma cells in bone marrow. J Clin Pathol 59: 927-929, 2006.

17. Thomas JO, Nijjar J, Turley H, Micklem K and Gatter KC: NB84: a new monoclonal antibody for the recognition of neuroblastoma in routinely processed material. J Pathol 163: 69-75, 1991.

18. Janet T, Ludecke G, Otten U and Unsicker K: Heterogeneity of human neuroblastoma cell lines in their proliferative responses to basic FGF, NGF, and EGF: correlation with expression of growth factors and growth factor receptors. J Neurosci Res 40: 707-715, 1995.

19. Nakagawara A: The NGF story and neuroblastoma. Med Pediatr Oncol 31: 113-115, 1998

20. Sonnenfeld $\mathrm{KH}$ and Ishii DH: Nerve growth factor effects and receptors in cultured human neuroblastoma cell lines. J Neurosci Res 8: 375-391, 1982.

21. Chen J, Chattopadhyay B, Venkatakrishnan G and Ross AH: Nerve growth factor-induced differentiation of human neuroblastoma and neuroepithelioma cell lines. Cell Growth Differ 1: 79-85 1990.

22. Chen J, Liu TH and Ross AH: Expression of recombinant NGF receptor in human neuroblastoma cell line without NGF receptor. Basic Med Sci Clin 11: 26-31, 1991. 